\title{
Romantic Relationships and Body Satisfaction Among Young Women
}

\author{
Charlotte N. Markey ${ }^{1}$ and Patrick M. Markey ${ }^{2}$
}

Received November 01, 2005; accepted November 10, 2005

Published online: 23 March 2006

\begin{abstract}
In the present study we examined associations between young women's romantic relationships and their body image. Ninety-five heterosexual couples (women's mean age $=22.46$ and men's mean age $=24.38$ ) participated in this study. We examined young women's satisfaction with their own bodies, their perceptions of their significant others' satisfaction with their bodies, and their significant others' actual satisfaction with their bodies using the Contour Drawing Rating Scale women's weight status was assessed using body mass index (BMI). Relationship constructs examined included relationship quality and the length of couples' romantic relationships. Results indicated that females were more dissatisfied with their bodies than they perceived their significant others to be and were more dissatisfied than their significant others actually were. Analyses further indicated that the longer women had been in a relationship with their significant other, the more likely they were to incorrectly believe that their significant other wanted them to look thinner.
\end{abstract}

KEY WORDS: body image; body satisfaction; romantic relationships; young adults.

\section{INTRODUCTION}

Sociocultural influences have long been implicated in girls' and women's development of body image. In particular, family, peer, media, and cultural influences have been examined as relevant to the development of women's body image and concerns about their physical appearance (Cash, 2003; Field et al., 1999; Markey, 2004). However, although young women's social experiences are increasingly likely to be comprised of romantic relationship experiences as they reach adulthood, surprisingly little research has examined the role that romantic partners may play in the development of young women's body image. The present study aims to extend past research examining sociocultural influences on the development of girls'

\footnotetext{
${ }^{1}$ Assistant Professor at Rutgers University. She received her PhD in psychology from the University of California at Riverside in 2002. Her research focuses on the development of body image and dieting behaviors and on understanding relations between personality and health. To whom correspondence should be addressed at Department of Psychology, Rutgers University, 311 North 5th Street, Camden, New Jersey, 08102; e-mail: chmarkey@camden.rutgers.edu.

${ }^{2}$ Assistant Professor at Villanova University. He received his $\mathrm{PhD}$ in psychology from the University of California at Riverside in 2002. His research focuses primarily on interpersonal theory.
}

and women's body image by examining young women's romantic relationships in association with their feelings about their bodies.

Past research suggests that sociocultural influences prompt women's concerns about their bodies by emphasizing the importance of women's physical appearance, particularly their body size (i.e., thinness; see Markey, 2004). The importance of physical appearance in women's development is also supported by research by Harter and colleagues (see Harter, 1999) suggesting that among adolescents, physical appearance contributes more to their sense of self-worth than any other factor; girls grow up realizing that their bodies are objects that others will look at and admire (Fredrickson and Roberts, 1997; Smolak, 2003). The developmental trajectory of girls' body satisfaction, with satisfaction appearing to decrease across childhood and adolescence (Cash and Henry, 1995; Smolak and Levine, 2001), highlights the growing concerns girls have about their bodies as they develop physically into women.

Western culture's narrowly defined standards of physical attractiveness that confront girls and women may contribute to the development of individual concerns about appearance (Brownell, 1991, Grogan and Richards, 
2002). Girls and women are unlikely to attain the thinideal presented to them in the media, are much more likely than men to receive negative criticism of their bodies, and are more likely than men to experience discrimination when they are overweight (Brownell, 1991; Murray et al., 1995; Wadden and Stunkard, 1985). Thus, young women are both socialized to accept that their body size is an integral component of their self-worth (Grover et al., 2003; Rodin, 1992), and are unlikely to achieve the standards they aspire to.

Concerns with achieving the thin-ideal are likely to become exacerbated during adolescence and young adulthood as women become increasingly interested in forming romantic relationships with members of the opposite sex. Girls and women no doubt assume what a fairly extensive body of research has confirmed-men are concerned with issues of physical appearances (including body size and shape) in their evaluation of potential romantic partners (e.g., Buunk et al., 2002; Buss, 1989; Singh, 1993; Singh and Young, 1995; Smith et al., 1990). Men have been found to report "looks" as more integral to their decision to become romantically involved with a significant other than do women (Buunk et al., 2002). Men's emphasis on physical appearance may be a result of socialization (i.e., learning) or adaptation (evolutionarily speaking; see Bjorntorp, 1988, 1991; Buss, 1989; Fredrickson and Roberts, 1997; Markey et al., 2002; Singh, 1993). Regardless, research suggests that women may actually underestimate what female body size is perceived as most attractive by men (Markey et al., 2004; Rozin and Fallon, 1988). There is even evidence to suggest that girls and women are more worried about the opposite sex's perceptions of their bodies than they need to be. Research by Rozin and Fallon (1988) first suggested that women believe men prefer thinner women than they actually do. This finding has been duplicated using different samples comprised of different age groups (e.g., Bergstrom et al., 2004; Collins, 1991). While men are likely to be observant of women's bodies - and perhaps even evaluative - they may not actually be as concerned about the relative thinness of women's bodies as girls and women might think they are.

Consistent with these findings, our past research (Markey et al., 2004) examining married women in their mid-late 30s, suggests that husbands may be much happier with their wives' bodies than wives are with their own bodies. In other words, results from our past research indicate that women are more dissatisfied with their own bodies than their husbands are with their wives' bodies. This apparent discrepancy between women's evaluations of their own bodies and their husbands' evaluations of their bodies suggests that the women in this study were not necessarily aware of whether or not their husbands were satisfied with their bodies. Of course, the generalizability of these results to young adult couples in the beginning stages of a relationship is still unknown; all of the couples in this past study had been married for a number of years and had children.

Some research suggests that women's relationship experiences (e.g., their sense of security or of being loved and valued) may predict women's body image (Friedman et al., 1999; Weller and Dziegielewski, 2004). For example, Friedman et al. (1999) found that marital satisfaction is associated with body satisfaction and Weller and Dziegielewski (2004) found that a positive, supportive relationship with a romantic partner is positively associated with women's body image and negatively associated with their anxiety about their physical appearance. However, Friedman et al. also found that relationship status (i.e., married vs. single) was not predictive of women's body satisfaction. Women's romantic relationship experiences may be associated with their body images, but research has yet to fully explain which elements of women's relationships (e.g., love, length of commitment) are conducive to the development of a positive body image. Further, research has yet to examine these issues among couples who are in stable, monogamous relationships that are relatively new (i.e., among couples who are not casually dating college students or long-term married couples).

It is important to examine associations between women's relationship experiences and their body images during the early adult years because this is a developmental period when social experiences shift from the family of origin and a more diffuse peer influence to focus on intimate relationships involving a partner or significant other. Individuals in their 20s report feeling "in between" the group influence of adolescence and stability of adulthood, and are often actively engaged in identity exploration, self-focus, and unstable intimate partnerships (Arnett, 2000). During this time of life, young adults are concerned with figuring out who they are, what they are doing with their lives, and specifically with whom they will be doing it. Thus, understanding associations between young women's body image concerns and romantic relationships is important given women's inclination to try to understand themselves and to form enduring romantic relationships during this developmental period.

\section{Aims and Hypotheses}

In the current study we extend prior research by examining body satisfaction ratings among young women and their romantic partners who are in relatively new, committed relationships and the romantic relationship 
correlates of these satisfaction ratings. Specifically, we address two primary research questions. First, in relatively new, committed romantic relationships, are young women's perceptions of their bodies similar or different than their romantic partners' perceptions? We hypothesized, consistent with previous research examining older married women, that young women would be more critical of their bodies (i.e., less satisfied with them) than their significant others would be. Second, in an attempt to further understand the role that romantic partners play in determining young women's body satisfaction, we also explored different elements of women's relationships: the length of their relationships and their relationship quality. We expected that women who reported higher levels of relationship quality would be more satisfied with their bodies, would think their partners were more satisfied with their bodies, and their partners would actually be more satisfied with their bodies than would women who reported experiencing lower levels of relationship quality. We also expected that the duration or length of the relationship would be associated with women's body image, such that women who had been in their relationships longer would experience a sense of security that would translate into higher body satisfaction scores.

\section{METHOD}

\section{Participants and Procedure}

Ninety-five heterosexual couples (95 women, mean age $=22.46$, range $=18-30$ years and 95 men, mean age $=24.38$, range $=18-35$ years) participated in the present study as part of a larger study examining associations between romantic relationships and health. This sample was predominantly European American. Seventy-five percent of men reported that they were of European-American backgrounds (11\% were African American, 7\% were Asian, and 7\% were Hispanic), and $69 \%$ of women reported that they were of EuropeanAmerican backgrounds (10\% were African American, $7 \%$ were Asian, $8 \%$ were Hispanic, and $6 \%$ were of an "other" ethnic background). Participants came from socioeconomically diverse backgrounds; $56 \%$ of men reported incomes under $\$ 20,000$ per year, $29 \%$ reported incomes between $\$ 20,000$ and $\$ 49,000$ per year, $11 \%$ reported incomes between $\$ 50,000$ and $\$ 75,000$, and $4 \%$ reported incomes over $\$ 75,000$ per year. Seventy-three percent of the women reported incomes under $\$ 20,000$ per year, 23\% reported incomes between $\$ 20,000$ and $\$ 49,000$ per year, and $4 \%$ reported incomes between $\$ 50,000$ and $\$ 75,000$. Twenty-one percent of men and $18 \%$ of women had completed high school, $44 \%$ of men and $40 \%$ of women had completed some college, $16 \%$ of men and $18 \%$ of women had received a bachelor's degree, and $19 \%$ of men and $24 \%$ of women had attended graduate school. In order to be eligible to participate in this study, all couples were required to have maintained exclusive, monogamous relationships for at least 1 year. Eligibility criteria also mandated that couples did not have children together. Forty-three percent of couples reported that they were dating and not cohabitating, $32 \%$ reported that they were cohabitating, and $25 \%$ reported that they were married.

Participants were recruited from a northeastern university campus and the surrounding area using fliers and advertisements; the resulting sample was comprised primarily of community participants. Participation in this study lasted approximately $1.5 \mathrm{~h}$ and included the completion of the measures used in this study amongst a variety of other measures that assessed health and relationship constructs. Participants were placed in separate rooms while they completed the measures. Couples were compensated with $\$ 50.00$, except for a minority $(14 \%)$ of the participants who elected to be compensated with $2 \mathrm{~h}$ of research credit for their Introductory Psychology course.

\section{Measures}

\section{Body Image}

The Contour Drawing Rating Scale (CDRS; Thompson and Gray, 1995) was used to assess perceptions of women's bodies. The version of this measure completed by the participants in this study consists of nine female figures that range from very underweight (a score of 1) to very overweight (a score of 9). Women were asked to select the figure that represents: (1) what they think they currently look like, (2) what they would like to look like, (3) what they think their romantic partners think they currently look like, and (4) what they think their romantic partners would like them to look like. The men in this study were asked to indicate (1) what they think their romantic partner currently looks like and (2) what they would like their romantic partner to look like. Men completed this measure in a separate room from their romantic partners. These six different ratings pertaining to women's bodies were used to calculate three body satisfaction scores. A measure of women's own body satisfaction was created by subtracting the figure selected in response to the question "Which figure looks most like you?" from "Which figure would you like to look like?" A measure of women's perceptions of their significant 
others' satisfaction with their bodies was created by subtracting the figure selected in response to the question "Which figure do you think your significant other thinks you look like?" from "Which figure do you think your significant other would like you to look like?" A measure of significant others' actual satisfaction with the women's bodies was created by subtracting the figure in response to the question "Which figure looks like your significant other?" from "Which figure would you like your significant other to look like?" Thus, it was possible to derive three body satisfaction scores for women: (1) own body satisfaction, (2) perceptions of significant others' satisfaction, and (3) significant others' actual satisfaction. For all three body satisfaction assessments, a score of 0 indicates satisfaction, a negative score indicates a desire to be thinner, and a positive score indicates a desire to be heavier. In previous research, the test-retest reliability for this measure was 0.79 (Thompson and Gray, 1995).

\section{Weight Status}

Because weight status is usually associated with women's body image, women's weight status was measured and operationalized using Body Mass Index scores (BMI; (weight $(\mathrm{kg}) / \mathrm{height}^{2}(\mathrm{~m})$ ). Based on the recommendations of Lohman et al. (1988) three height and weight measurements were collected for each woman by a trained research assistant. Women's average weight and height were used to calculate their BMIs. In this sample, women's average $\mathrm{BMI}$ was $23.99(\mathrm{SD}=4.95)$.

\section{Relationship Measures}

Women's perception of their relationship quality was assessed via the 15-item Marital Interactions Scale (MIS; Braiker and Kelley, 1979). This measure assesses both relationship love (e.g., "How committed do you feel towards your partner?") and harmony (i.e., low conflict; e.g., "How often do you and your partner argue with one another?"). Past research using the MIS has found that it provides a valid and reliable assessment of relationship quality (e.g., Aronson and Huston, 2004; Grote et al., 2004; Markey et al., 2001; Proulx et al., 2004; Specher and Hendrick, 2004; Volling et al., 2002). Because this measure was originally designed for use with married couples, language in the measure was revised slightly to indicate that women were evaluating their relationship with their significant other (although not, necessarily, a spouse). The reliability of the MIS in the current study was 0.85 .

The length or duration of couples' relationships was assessed by the survey question, "How long have you been romantically involved with your significant other here with you today?" Women's responses were rounded to the nearest month, and this item was used as an indicator of participants' perceptions of the length of their relationships. On average, couples that participated in this study had been romantically involved for 3.13 years $(\mathrm{SD}=2.07)$.

\section{RESULTS}

\section{Women's Body Satisfaction and Men's Satisfaction With Their Romantic Partners' Bodies}

Analyses were first conducted to compare women's body satisfaction to their perceptions of their romantic partners' satisfaction with their bodies and their romantic partners' actual satisfaction with their bodies. On average, women thought their bodies looked heavier $(M=5.26$, $\mathrm{SD}=1.86)$ than they thought their romantic partners' perceived them to look $(M=4.84, \mathrm{SD}=1.84 ; t(94)=4.99$, $p<0.01$ ), and than their romantic partners actually thought they looked $(M=4.98, \mathrm{SD}=1.65 ; t(94)=2.06, p<0.05)$. Additionally, women's desired body figure $(M=3.88$, $\mathrm{SD}=1.27$ ) tended to be thinner than the body figure they perceived their romantic partner wanted them to look like $(M=4.12, \mathrm{SD}=1.58)$ and their romantic partners' actual desired female figure $(M=4.51, \mathrm{SD}=1.24 ; t(94)=1.99$, $p<0.05 ; t(94)=4.11, p<0.01$, respectively). Because the women in this study tended to think they were heavier than their romantic partners perceived them to be and wanted to be thinner than their romantic partners desired them to be, it is consistent that they also tended to be more dissatisfied with their bodies than their romantic partners. Specifically, women tended to be less satisfied with their own bodies (i.e., the discrepancy between desired and perceived actual figure; $M=-1.37, \mathrm{SD}=1.48)$ than their romantic partners' were with their bodies $(M=-0.72, \mathrm{SD}=1.73$; $t(94)=3.85, p<0.01)$. Women also tended to be less satisfied with their own bodies than they perceived their romantic partners to be with their bodies $(M=-0.72$, $\mathrm{SD}=1.73 ; t(94)=3.85, p<0.01)$.

\section{Women's Romantic Relationships and Body Satisfaction}

Correlational analyses were conducted to determine if relations existed between the three assessments of women's body satisfaction, the quality of their romantic relationship, and the length of their romantic relationship. Because women's age and body size (i.e., BMI) may be 
Table I. Correlation Analyses of Women's Body Satisfaction Scores, Age, BMI, Relationship Quality, and Relationship Length

\begin{tabular}{lccccccc}
\hline & 1 & 2 & 3 & 4 & 5 & 6 & 7 \\
\hline 1. Women's age & - & $0.27 *$ & -0.07 & $0.50^{* *}$ & 0.03 & $-0.21 *$ & -0.12 \\
2. Body mass index & & - & -0.12 & 0.11 & $-0.50^{* *}$ & $-0.27^{* *}$ & $-0.47^{* *}$ \\
3. Relationship quality & & & - & -0.09 & 0.02 & -0.06 & 0.00 \\
4. Relationship length & & & & - & 0.03 & $-0.27^{*}$ & -0.06 \\
5. Own body satisfaction & & & & & - & $0.48^{* *}$ & $0.46^{* *}$ \\
6. Perceived partners' satisfaction & & & & & - & $0.40^{* *}$ \\
7. Partners' actual satisfaction & & & & & & - \\
\hline
\end{tabular}

Note. $n=95$.

${ }^{*} p<0.05 ;{ }^{* *} p<0.01$.

associated with their body satisfaction and relationship experiences, these two variables were also included in these analyses. As seen in Table I, women's own body satisfaction, their perceptions of their partners' satisfaction, and their partners' actual satisfaction were associated with women's BMI. Additionally, women's age was positively related to their BMI and the length of their relationship was inversely related to their perceived partners' body satisfaction. Contrary to our hypothesis that a loving and harmonious relationship would be associated with a positive body image, none of the correlations between relationship quality and the three assessments of body satisfaction were significant. Furthermore, relationship length was negatively associated with women's perceived partners' satisfaction. In other words, women who thought their romantic partners were unsatisfied with their bodies not only had relatively high BMIs but were also older in age and had been romantically involved with their partners longer than women who thought their partners were satisfied with their bodies.

Multiple regression analyses were conducted in order to determine if relationship length predicted women's perceptions of their partner's satisfaction with their bodies beyond the variance explained by women's age and BMI. As shown in Table II, women's relationship length uniquely predicted women's perceptions of their partners' satisfaction with their bodies.

Table II. Simultaneous Regression Analysis Predicting Women's Perceptions of Their Romantic Partners' Satisfaction With Their Bodies

\begin{tabular}{lccl}
\hline Predictors & $B$ & $\mathrm{SE} B$ & $\begin{array}{l}\text { Semipartial } \\
\text { correlation }\end{array}$ \\
\hline Intercept & 3.46 & & \\
Age & 0.00 & 0.06 & -0.01 \\
Body mass index & -0.09 & 0.04 & $-0.26^{*}$ \\
Relationship quality & -0.30 & 0.29 & -0.09 \\
Relationship length & -0.21 & 0.09 & $-0.23^{*}$ \\
\hline
\end{tabular}

Note. Multiple $R=.38, p<0.001, n=95$.

${ }^{*} p<0.05$.
Although the previous analysis suggests that women who had been in a relationship for relatively longer tended to think their romantic partners were less satisfied with their bodies, it is not clear which element of body satisfaction was responsible for this association. Because women's perceptions of their partners' satisfaction with their bodies was operationalized using two figure selections (the figure women selected to represent what their romantic partners thought they currently looked like and the figure women selected to represent what their romantic partners would like them to look like) this finding may have occurred due to two different reasons. It is possible that women in relationships for a relatively longer period of time thought that their partners were more dissatisfied with their bodies because they perceive them to be heavier than the women who have been in relationships for shorter periods of time. Or, it is possible that women in relatively longer term relationships feel their partners have a thinner ideal body type than women in newer (shorter-term) relationships. Additional regression analyses were computed to investigate which of these two elements contributed to the association between relationship length and women's declining perception of their partners' satisfaction with their bodies. As seen in Table III, relationship length was not related to women's perceptions of how their romantic partners thought they currently looked $(\mathrm{sr}=-0.02$, $p>0.05$ ), but was significantly related to the ideal figure women thought their romantic partners wanted like them to look like ( $\mathrm{sr}=-0.26, p<0.05$ ). To better understand how these two figure selections contributed to the negative relationship found between women's perceptions of their partners' satisfaction with their bodies and relationship length, Fig. 1 simultaneously displays the plot of the regression equations that predict the "Figure women reported their significant others thought they currently looked like" and the "Figure women reported their significant others would like them to look." In the regression equations used to create this figure all predictor variables (except relationship length) were set at their 
Table III. Simultaneous Regression Analyses Predicting the Figure Women Reported their Significant Others Thought they Currently Looked like and the Figure Women Reported Their Significant Others Would Like Them to Look Like

\begin{tabular}{|c|c|c|c|c|}
\hline Body figure selected & Predictors & $B$ & SE $B$ & Semipartial correlation \\
\hline \multirow{4}{*}{$\begin{array}{l}\text { Figure women reported their significant others thought } \\
\text { they currently looked like }{ }^{a}\end{array}$} & Intercept & -2.68 & & \\
\hline & Age & 0.01 & 0.05 & 0.03 \\
\hline & Body mass index & 0.26 & 0.03 & $0.66^{* *}$ \\
\hline & Relationship quality & 0.27 & 0.21 & 0.13 \\
\hline \multirow{4}{*}{$\begin{array}{l}\text { Figure women reported their significant others would } \\
\text { like them to look like } b\end{array}$} & Age & 0.01 & 0.05 & 0.02 \\
\hline & Body mass index & 0.17 & 0.03 & $0.49^{* *}$ \\
\hline & Relationship quality & -0.03 & 0.21 & -0.02 \\
\hline & Relationship length & -0.23 & 0.08 & $-0.26^{* *}$ \\
\hline
\end{tabular}

Note. Construct of primary interest is in italic font.

${ }^{a}$ Multiple $R=.69, p<0.001$.

${ }^{b}$ Multiple $R=.56, p<0.001$.

$n=95$.

${ }^{*} p<0.05 ;{ }^{* *} p<0.01$.

means. As shown in Fig. 1, women in longer relationships did not think their partners' thought they looked heavier than women in shorter relationships. Instead, they believe their partners want them to look thinner than women who are in relationships that have been of a shorter duration.

\section{DISCUSSION}

In the present study we examined young women's satisfaction with their own bodies, their perceptions of their significant others' satisfaction with their bodies, and their significant others' actual satisfaction with their bodies. Comparisons between men's and women's ratings of the women's bodies were then made. These analyses build on our past research (e.g., Markey et al., 2004) by studying these issues in a sample of young adult couples who were in committed, but relatively new relationships rather than couples that were in longer-term marriages. Second, in an attempt to further understand the role that romantic relationships play in determining women's body satisfaction, we explored associations among women's body

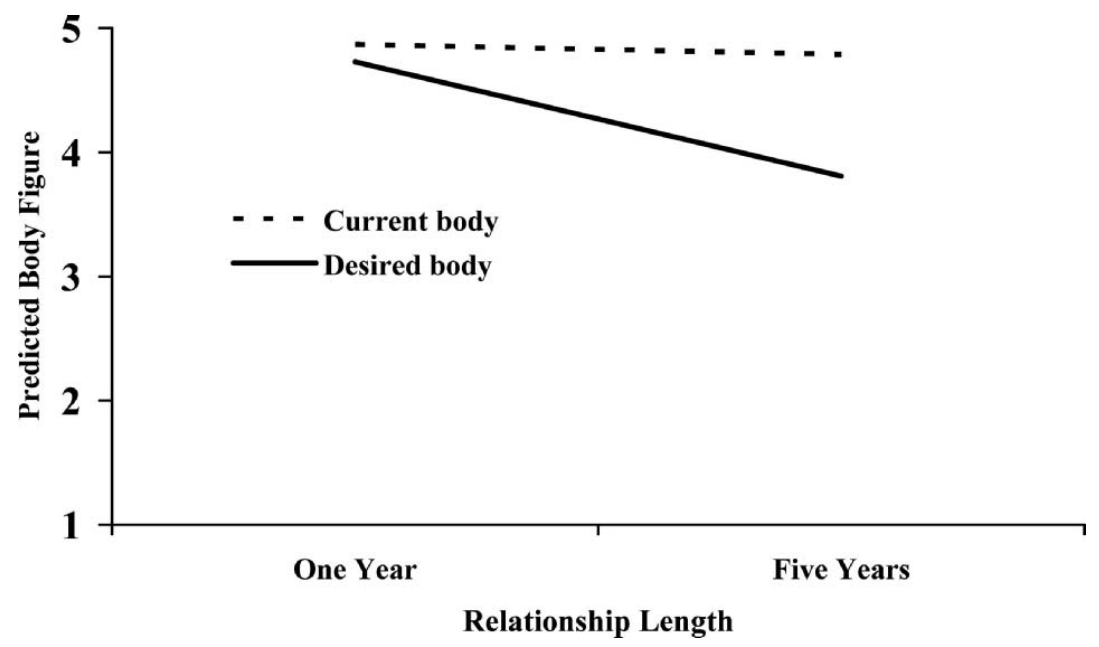

Fig. 1. Graphical representation of the regression analyses examining the relations between women's perception of their romantic partners' satisfaction with their bodies and the length of their romantic relationship. Note. Graphic representations of the equations to predict the figure women reported their significant other thought they looked like (current body) and the figure women reported their significant other wanted them to look like (desired body.) 
satisfaction scores and women's relationship quality and relationship length. These analyses extend past findings (e.g., Friedman et al., 1999; Weller and Dziegielewski, 2004) that have linked women's relationship experiences and their body image.

The findings from the present study are consistent with those of past reports (e.g., Collins, 1991; Markey et al., 2004; Rozin and Fallon, 1988) that indicate women tend to be more dissatisfied with their bodies than men are with women's bodies. As was hypothesized, women's significant others were generally more satisfied with their romantic partners' bodies than the women were with their own bodies. It appears that even in relatively new relationships (presumably, complete with the courting and compliments that accompany a new relationship) young adult men's satisfaction with their romantic partners' appearance does not correspond to the self-critical nature of women's attitudes towards their own bodies.

Correlational analyses suggested that women's body size (i.e., body mass index) was associated with women's own body satisfaction and that body size was associated with women's perceptions of their romantic partners' satisfaction with their bodies. In credit to the accuracy of women's perceptions of the importance of relative body size, body size was associated with men's actual report of satisfaction with their partners' bodies. However, the current study found that women's body size was not related to either relationship quality or relationship length. Further, contrary to the hypothesis that a loving and harmonious intimate relationship would be associated with a positive body image, we did not find any significant correlations between women's reports of the quality of their relationships and their own body satisfaction, their perceptions of their partners' satisfaction with their bodies, or the men's own reports of actual satisfaction with their bodies. It appears that variations in women's body satisfaction are not associated with variations in their relationship quality. This finding may indicate that even women who are in loving and harmonious relationships are not buffered from the sociocultural idealization of a thin body.

The current study found that women's perceptions of their partners' satisfaction with their bodies was inversely related to the duration of the romantic relationships. This finding was in contrast to our prediction that the length of women's relationships would be positively associated with their body image due to a positive association between women's sense of security in their romantic relationships and their sense of security about their bodies. Instead, it appears that the longer women had been in a relationship with their partners, the less likely they were to think that their partners were satisfied with their bodies.
This relation remained significant even after controlling for women's age and body size (i.e., BMI). Women in relatively longer relationships were more likely to believe that their partners were unsatisfied with their bodies than were women in relatively newer onset, shorter relationships. Further analyses revealed that the inverse association between the length of women's relationships and their perceptions of their partners' satisfaction with their bodies occurred because women in longer relationships believed their partners want them to look thinner than women who were in relationships that were of a shorter duration.

Interestingly, an association between women's romantic partners' actual satisfaction with their bodies and the length of their relationships was not found. Across time in a relationship, these men did not appear to become less satisfied with their significant others' bodies. So, why might women incorrectly believe that their romantic partners want them to be thinner the longer they are in a relationship with them? It is possible that the longer a woman is in a relationship with her partner, the more likely she is to project her own sense of an "ideal body" onto her partner or assume that he shares the same ideal that she does. Women's perceptions of the ideal body appear to be deeply engrained, originating early in life, and encouraged by media messages depicting an ideal that is usually unobtainable (Davison et al., 2000; Levine and Smolak, 1996; Stice et al., 2001). Thus, it is plausible that women assume that meaningful others in their lives share their body ideals and are dissatisfied with their bodies, especially as these others (in this case, male romantic partners) become more familiar with their bodies. It is also possible that women gradually start to receive less positive feedback about their appearance from their partners as their relationships progress. At the very beginning of a relationship, a man may be careful to compliment his girlfriend's appearance, and specifically, her body. However, with increased familiarity and stability in a relationship, perhaps men are less likely to freely offer these compliments. This may leave women to assume that their significant others are less satisfied with their bodies than they once were, and desire them to be thinner than they once did.

\section{Limitations}

Although the present study contributes to the literature as one of the first attempts to investigate associations between young women's romantic relationships and body satisfaction, some limitations of this study warrant mention. The primary limitation concerns the correlational and cross-sectional nature of the design employed. It is not possible to conclusively discern if, for example, the 
length of women's relationships is causing their perceptions of their romantic partners' satisfaction with their bodies to change. It is hoped that future research endeavors will replicate and extend these findings by longitudinally studying diverse couples. Further, additional measures of couples' relationships, perhaps including behavioral analyses of couples' relationships (i.e., not only self-report measures), would strengthen this research and contribute to researchers' understanding of the associations between women's romantic relationship experiences and their body image.

\section{Implications}

Young women, such as those in this study, are likely to be concerned about the appearance of their bodies (Cash and Henry, 1995) and are likely to be concerned with establishing romantic relationships with members of the opposite sex (Arnett, 2000). These two concerns may be integral to their experience of young adulthood. However, associations between young women's body image and their romantic relationships have received little empirical attention. This study suggests that men could play a positive role in their romantic partners' developing body images during this time of life. It appears that men are less critical of their romantic partners' bodies than women are of their own bodies. Thus, given that young women may be their own worse critics, communication about body image issues among romantic partners may have the potential to help women feel better about their bodies. It is possible that men are afraid to broach this topic with their significant others, and in the absence of communication about these issues, women may be making inaccurate assumptions about how their romantic partners view their bodies. Results from the current study suggest that these assumptions may become increasingly erroneous as time passes in a relationship. Instead of feeling more secure about their physical appearance with the passage of time in a relationship, it appears that young women may feel less confident about how their bodies are perceived by their romantic partners. For young women who are dissatisfied with their bodies, therapy that involves their romantic partners may enhance their ability to communicate with their partners about body image issues and may facilitate their development of a healthy romantic relationship and a healthy body image.

\section{ACKNOWLEDGMENTS}

The research described in this report was supported by an award to Charlotte Markey from Rutgers Univer- sity and an award to Patrick Markey from Villanova University. These findings were presented at the Society for Research in Child Development Conference in Atlanta in April, 2005. The authors thank Jeanine Caso, Sara DiMascio, Heather Fishman, Constance Gladney, Alexann Masiko-Meyer, Laura Tayloe, Michele Trivelli, and Jacqueline Siracuse for their help with data collection.

\section{REFERENCES}

Arnett, J. J. (2000). Emerging adulthood: A theory of development from the late teens through the twenties. Am. Psychol. 55(5): 469-480.

Aronson, S. R., and Huston, A. C. (2004). The mother-infant relationship in single, cohabitating, and married families: A case for marriage? $J$. Fam. Psychol. 18(1): 5-18.

Bergstrom, R. L., Neighbors, C., and Lewis, M. A. (2004). Do men find "bony" women attractive?: Consequences of misperceiving opposite sex perceptions of attractive body image. Body Image 1(2): 183-191.

Bjorntorp, P. (1988). The associations between obesity, adipose tissue distribution and disease. Acta Medica Scand. (Supp.) 723: 121-134.

Bjorntorp, P. (1991). Adipose tissue distribution and function. Int. J. Obesity 15: 67-81.

Braiker, H. B., and Kelley, H. H. (1979). Conflict in the development of close relationships. In Burgess, R., and Houston, T. (eds.), Social Exchange in Developing Relationships. Academic Press, New York, pp. 135-168.

Brownell, K. D. (1991). Dieting and the search for the perfect body: Where physiology and culture collide. Behav. Ther. 22: 1-12.

Buss, D. M. (1989). Sex differences in human mate preferences: Evolutionary hypotheses tested in 37 cultures. Behav. Brain Sci. 12(1): $1-49$.

Buunk, B. P., Dijkstra, P., Fetchenhauer, D., and Kenrick, D. T. (2002) Age and gender differences in mate selection criteria for various involvement levels. Personal Relationships 93(3): 271-278.

Cash, T. F. (2003). Body image: Past, present, future. Body Image 1: $1-5$.

Cash, T. F., and Henry, P. E. (1995). Women's body images: The results of a national survey in the USA. Sex Roles 22: 19-28.

Collins, M. E. (1991). Body figure perceptions and preferences among preadolescent children. Int. J. Eat. Disord. 10: 199-208.

Davison, K. K., Markey, C. N., and Birch, L. L. (2000). Etiology of body dissatisfaction and weight concerns among 5-year-old girls. Appetite 35: 143-151

Field, A. E., Cheung, L., Wolf, A. M., Herzog, D. B., Gortmaker, S. L., and Colditz, G. A. (1999). Exposure to the mass media and weight concerns among girls. Pediatrics 103(3): E36.

Fredrickson, B. L., and Roberts, T. (1997). Objectification Theory: Toward understanding women's lived experiences and mental health risks. Psychol. Women Q. 21: 173-206.

Friedman, M. A., Dixon, A. E., Brownell, K. D., Whisman, M. A., and Wilfley, D. E. (1999). Marital status, marital satisfaction, and body image dissatisfaction. Int. J. Eating Disord. 26: 81-85.

Grogan, S., and Richards, H. (2002). Body image: Focus groups with boys and men. Men and Masculinities 4: 219-232.

Grote, N. K., Clark, M. S., and Moore, A. (2004). Perceptions of injustice in family work: The role of psychological distress. J. Fam. Psychol. 18(3): 480-492.

Grover, V. P., Keel, P. K., and Mitchell, J. P. (2003). Gender differences in implicit weight identity. Int. J. Eating Disord. 34: 125-135.

Harter, S. (1999). The Construction of the Self: A Developmental Perspective. Guilford, New York.

Levine, M. P., and Smolak, L. (1996). Media as a context for the development of disordered eating. In Smolak, L., Levine, M. P., and 
Striegel-Moore, R. (eds.), The Developmental Psychopathology of Eating Disorders. Erlbaum, Hillsdale, NJ, pp. 183-204.

Lohman, T. G., Roche, A. F., and Martorell, M. (1988). Anthropometric Standardization Reference Manual. Human Kinetics, Champaign, IL.

Markey, C. N. (2004). Culture and the Development of Eating Disorders: A Tripartite Model. Eating Disord.: J. Treat. Prev. 12: 139-156.

Markey, C. N., Markey, P. M., and Birch, L. L. (2001). Interpersonal predictors of dieting practices among married couples. J. Fam. Psychol. 15: 464-475.

Markey, C. N., Markey, P. M., and Birch, L. L. (2004). Understanding women's body satisfaction: The role of husbands. Sex Roles 51: 209216.

Markey, C. N., Tinsley, B. J., Ericksen, A. J., Ozer, D. J., and Markey, P. M. (2002). Preadolescents' perceptions of females' body size and shape: Evolutionary and social learning perspectives. J. Youth Adolesc. 31: 137-146.

Murray, S. H., Touyz, S. W., and Beumont, P. J. V. (1995). The influence of personal relationships on women's eating behavior and body satisfaction. Eating Disord. 3: 243-252.

Rodin, J. (1992). Body Traps. Morrow, New York.

Rozin, P., and Fallon, A. (1988). Body image, attitudes toward weight, and misperceptions of figure preferences of the opposite sex: A comparison of men and women in two generations. J. Abnorm. Psychol. 97: 342-345.

Singh, D. (1993). Adaptive significance of female physical attractiveness: Role of waist-to hip ratio. J. Pers. Soc. Psychol. 65(2): 293-307.

Singh, D., and Young, R. K. (1995). Body weight, waist-to-hip ratio, breasts, and hips: Role in judgments of female attractiveness and desirability for relationships. Ethol. Sociobiol. 16: 483-507.

Smith, J. E., Waldorf, V. A., and Trembath, D. L. (1990). "Single White male looking for thin, very attractive...". Sex Roles 23: 675-685.

Smolak, L. (2003). Body image in children and adolescents: Where do we go from here? Body Image 1: 15-28.

Smolak, L., and Levine, M. P. (2001). Body image in children. In Thompson, J. K., and Smolak, L. (eds.), Body Image, Eating Disorders, and Obesity in Youth: Assessment, Prevention, and Treatment. American Psychological Association, Washington DC, pp. 41-66.

Specher, S., and Hendrick, S. S. (2004). Self-disclosure in intimate relationships: Assocations with individual and relationship characteristics over time. J. Soc. Clin. Psychol. 23(6): 857-877.

Stice, E., Spangler, D., and Agras, W. S. (2001). Exposure to mediaportrayed thin-ideal images adversely affects vulnerable girls: A longitudinal experiment. J. Soc. Clin. Psychol. 13: 288-303.

Thompson, M. A., and Gray, J. J. (1995). Development and validation of a new body image assessment scale. J. Pers. Assess. 64: 258-269.

Volling, B. L., McElwain, N. L., and Miller, A. L. (2002). Emotion regulation in context: The jealousy complex between young siblings and its relations with child and family characteristics. Child Dev. 73(2): 581-600

Wadden, T. A., and Stunkard, A. J. (1985). Social and psychological consequences of obesity. Ann. Intern. Med. 103: 1062-1067.

Weller, J. E., and Dziegielewski, S. F. (2004). The relationship between romantic partner support styles and body image disturbance. J. Hum. Behav. Soc. Environ. 10(2): 71-92. 